\title{
Is there liability if you don't test for BRCA?
}

\author{
Cases involving missed $B R C A$ testing are increasing. Could you be \\ exposing yourself to unnecessary risk if you don't counsel for and \\ recommend genetic testing for a patient with red flags for breast cancer?
}

\author{
Joseph S. Sanfilippo, MD, MBA, and Steven R. Smith, MS, JD
}

\begin{abstract}
CASE Young woman with family history of breast cancer detects lump

Two weeks after noting a lump on her breast when her cat happened to jump on her in that spot, a 28-year-old woman (G0) went to her primary care provider. She was referred to her gynecologist; breast imaging, ultrasonography, and mammography were obtained, with microcalcifications noted. A fine needle aspiration diagnosed intraductal malignancy. The surgical breast tissue specimen was estrogen receptor (ER)- and progestogen receptor (PR)-positive and HER2-negative. Other tumor markers were obtained, including carcinoembryonic antigen, and tissue polypeptide specific antigen, p53, cathepsin D, cyclin E, and nestin, but results were not available.
\end{abstract}

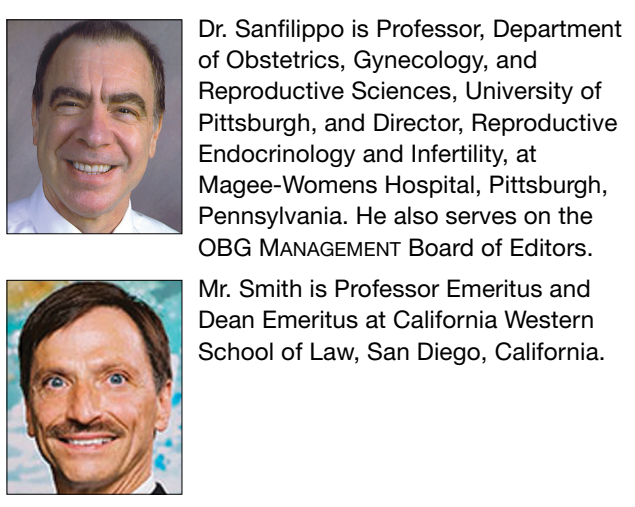

The authors report no financial relationships relevant to this article.

10.12788/obgm.0077
With regard to family history, the woman's mother and maternal grandmother had a history of breast cancer. The patient and her family underwent gene testing. The patient was found to be BRCA1- and BRCA2-positive; her mother was BRCA1-positive, an older sister was BRCA2positive, and her grandmother was not tested.

The question arose in light of her family history as to why she was not tested for BRCA and appropriately counseled by her gynecologist prior to the cancer diagnosis. Litigation was initiated. While the case did not go forward regarding litigation, it is indeed a case in point. (Please note that this is a hypothetical case. It is based on a composite of several cases.)

\section{Medical considerations}

Breast cancer is the most common type of cancer affecting women in the Western world. ${ }^{1}$

Advances in clinical testing for gene mutations have escalated and allowed for identification of patients at increased risk for breast and ovarian cancer. Along with these advances come professional liability risk. After looking at the medical considerations for $B R C A 1$ and 2 testing, we will consider a number of important legal issues. In the view of some commentators, the failure to diagnose genetic mutations in patients predisposed to cancer is "poised to become the next wave of medical professional liability lawsuits." ${ }^{2}$

$B R C A 1$ and BRCA2 genes provide tumor suppressor proteins, and assessment for
IN THIS ARTICLE

Guidelines for genetic testing

page 40

Malpractice and $B R C A$

page 42

Liability

in the

case

example

page 43 


\section{FIGURE Mayo Clinic model of risk assessment for breast cancer ${ }^{5}$}

Step 1: Assess family history

- Use either USPSTF or NCCN approach

- USPSTF (2019): Ask about personal or family history of BRCA-related (breast, ovarian, tubal, or peritoneal) cancer or ancestry. If present, use a brief familial risk assessment tool (eg, 7-question family history screening or B_RST)

- NCCN (2019): Ask about all cancers diagnosed in first- or second-degree relatives, including type of cancer and age of diagnosis

- If the family history screen is positive using either tool, then refer patient to genetic counseling

- Patients with a high-risk genetic mutation -> highrisk screening protocol and referral to discuss riskreducing medications and/or surgical prophylaxis

- If family history screen is negative, and/or genetic testing is negative/equivocal, continue to step 2 .

Step 2: Assess personal history

- Demographics

- Age

- Ethnicity

- Hormonal risk factors

- Age of menarche/menopause

- Age at first live birth/nulliparity
- Exogenous hormone use

- Obesity

- Radiographic breast density

- BIRADS category C or D

- Other (Proceed directly to high-risk screening protocol if either of the following are present):

- Previous breast biopsy with atypical ductal hyperplasia or lobular carcinoma in situ

- History of chest radiation between ages of 10-30

Step 3: Choose a prediction model

- $\mathrm{NCl}$ Gail Model can be used in the context of risk-reducing medications, otherwise routine use is not recommended

- BCSC tool is appropriate for most patients, with a few notable exceptions

- IBIS/Tyler Cuzick should be used if family history of:

- Young age $(<50)$ at diagnosis

- Second-degree relative with cancers

- Male breast cancers

- Ovarian cancer

Step 4: Interpret risk assessment as average, moderate, or high to inform screening strategy and whether patient should be offered risk-reducing medications

Abbreviations: B_RST, Breast Cancer Genetics Referral Screening Tool; BCSC, Breast Cancer Surveillance Consortium; BIRADS, Breast imaging-reporting and data system; IBIS, International Breast Cancer Intervention Study Model; NCI, National Cancer Institute; NCCN, National Comprehensive Cancer Network; USPSTF: US Preventive Services Task Force.

mutations is recommended for individuals at high risk for breast and/or ovarian cancer; mutations in BRCA genes cause DNA damage, which increases the chance of developing cancer. The other way to look at it is, BRCA1 and 2 are tumor suppressor genes that are integrally involved with DNA damage control. Once there is a mutation, it adversely affects the beneficial effects of the gene. Mutations in these genes account for $5 \%$ to $10 \%$ of all hereditary breast cancers. ${ }^{3}$ Of note, men with $B R C A 2$ are at increased risk for prostate cancer.

A patient who presents to her gynecologist stating that there is a family history of breast cancer, without knowledge of genetic components, presents a challenge (and a medicolegal risk) for the provider to assess. Prediction models have been used to determine specific patient risk for carrying a genetic mutation with resultant breast cancer development. ${ }^{4}$ Risk prediction models do not appear to be a good answer to predicting who is more likely to develop breast or ovarian cancer, however. A Mayo model may assist (FIGURE). ${ }^{5}$ Clinicians should also be aware of other models of risk assessment, including the Gail Model (TABLE 1). ${ }^{6}$

\section{Guidelines for genetic testing}

The American College of Obstetricians and Gynecologists states that patient medical history and family history are paramount in obtaining information regarding risk for breast and ovarian cancer. First- and seconddegree relatives are allocated to this category. Information regarding age of diagnosis, maternal and paternal lineage, and ethnic background can imply a need for genetic 
TABLE 1 Gail Model of risk assessment for breast cancer ${ }^{6}$

\begin{tabular}{lll}
\hline Model & \multicolumn{1}{c}{ Risk factors } & \multicolumn{1}{c}{ Comments } \\
\hline Gail & $\begin{array}{l}\text { Age, age at birth of first child (if applicable), } \\
\text { family history of breast cancer (mother, } \\
\text { sister, daughter), number of past breast } \\
\text { biopsies, number of biopsies showing } \\
\text { atypical hyperplasia, race/ethnicity }\end{array}$ & $\begin{array}{l}\text { Risk is underestimated in women with a } \\
\text { genetic predisposition }\end{array}$ \\
\hline Gail 2 & $\begin{array}{l}\text { History of affected 1st-degree family } \\
\text { member, in addition to Gail risk factors } \\
\text { listed above }\end{array}$ & $\begin{array}{l}\text { Used extensively in clinical practice; most } \\
\text { accurate in non-Hispanic White women } \\
\text { receiving annual mammography; low } \\
\text { sensitivity }\end{array}$ \\
\hline
\end{tabular}

\section{TABLE 2 Candidates for genetic testing for hereditary breast and ovarian cancer syndrome ${ }^{7,8}$}

Women with a personal history of the following type(s) of cancer:

- Epithelial ovarian, tubal, or peritoneal cancer

- Breast cancer $\leq$ age 45

- Breast cancer and close relative with breast cancer at $\leq$ age 50 or close relative with epithelial ovarian, tubal, or peritoneal cancer at any age

- Breast cancer $\leq$ age 50, with limited or unknown family history

- Breast cancer and 2 or more close relatives with breast cancer at any age

- Breast cancer and 2 or more close relatives with pancreatic cancer or aggressive prostate cancer

- Two breast cancer primaries, the first diagnosed $\leq$ age 50

- Triple-negative breast cancer $\leq$ age 60

- Breast cancer and Ashkenazi Jewish ancestry at any age

- Pancreatic cancer and 2 or more close relatives with breast, ovarian, tubal, or peritoneal cancer; pancreatic cancer; or aggressive prostate cancer

Women without cancer but with one or more of the following:

- First-degree relative or several close relatives that meet the aforementioned criteria

- Close relative carrying a known BRCA1 or BRCA2 mutation

- Close relative with male breast cancer

testing (TABLE 2). ${ }^{7,8} \mathrm{~A}$ number of genetics national organizations have participated in recommendations and include the American College of Medical Genetics and Genomics, the National Society for Genetic Counselors, and the Society of Gynecologic Oncology. ${ }^{\text {? }}$

The question always surfaces, could the clinical outcome of the cancer when diagnosed have been changed if screening were undertaken, with earlier diagnosis, or prevented with prophylactic mastectomy, and changed the end result. In addition, it is well known that breast augmentation mammoplasty alters the ability to accurately evaluate mammograms. Patients considering this type of plastic surgery, ideally, should be counselled accordingly. ${ }^{9}$

Bottom line, we as clinicians must be cognizant of both ACOG and United States Preventive Services Task Force (USPSTF) recommendations regarding screening and gene testing for women considered high risk for breast cancer based on family history. ${ }^{7}$

\section{Legal considerations}

The case presented demonstrates that the discovery of the BRCA1 and BRCA2 genes, 
$\overline{\text { FAST }}$

TRACK

To prevail in a malpractice case, the plaintiff needs to demonstrate the physician's duty and breach of that duty, damages, and causation and reliable tests for determining the existence of the genes, brought with them legal issues as well as medical advantages. We look at professional liability (malpractice) questions this technology raises, and then consider the outcome of the hypothetical case. (BRCA is used here to apply broadlynot only to BRCA1 and 2 but also to $P A L B 2$, CHEK2, and similar genetic abnormalities.)

To date, the most visible BRCA legal issues covered in cases and law reviews have focused more on patent law than malpractice. The most important of these was a decision of the US Supreme Court in Association for Molecular Pathology $v$ Myriad Genetics. ${ }^{10}$ The US Patent Office was granting patents to companies finding useful, naturally occurring segments of human DNA, and had granted Myriad several patents on $B R C A 1$ and BRCA2 genes. This patent policy had the potential to seriously interfere with broad scientific use of these genes. ${ }^{11}$ Fortunately, the Supreme Court stepped in and unanimously invalidated such patents. It held that a "naturally occurring DNA segment is a product of nature and not patent eligible merely because it has been isolated." The Court noted, "Finding the location of the $B R C A 1$ and BRCA2 genes does not render the genes patent eligible 'new ... composition[s] of matter."' ${ }^{\prime \prime}$ The Court did allow the patenting of tests for specific gene structures, and artificial changes in naturally occurring genes.

\section{Malpractice and $B R C A$}

While the $B R C A$ patent wars have lingered, the potential for a significant increase in $B R C A$-related malpractice cases is of increasing concern. Like most malpractice liability, these new claims are based on very old principles of negligence. ${ }^{12}$ To prevail, the plaintiff (ordinarily, an injured patient) must demonstrate 4 things:

- A duty. That is, the physician owed a duty to the injured party. Usually (but not always) that requires a professional relationship between the physician and the person injured.

- A breach of that duty. Malpractice liability is based on the fact that the physician did something that a reasonably careful physician (generally, of the same specialty) would not have done, or that the physician failed to do something that a reasonable physician would have done. This usually means that the profession itself sees what the physician did (or did not do) as medically inappropriate. In medical malpractice cases, that is ordinarily measured by what the usual or common practice is among prudent physicians. In rare circumstances, courts have found the standard practice of a profession to be negligent. Where, for example, it was custom for a professional not to give an eye pressure test to anyone under age 40 , a court found that common standard to be inappropriate. ${ }^{13}$ In the words of Judge Learned Hand (speaking about a different case), "a whole calling may have unduly lagged in the adoption of new and available devices. It never may set its own tests." ${ }^{14}$ Underlying negligence is a cost-benefit analysis (discussed below).

- Damages. There must have been some damage that courts recognize, usually loss of money or opportunity to work, the cost of care, pain and suffering, or loss of enjoyment/quality of life. In malpractice, many states now recognize the "loss of chance" or the "loss of a chance." That means, if a "physician negligently fails to diagnose a curable disease, and the patient is harmed by the disease, the physician should be liable for causing the 'loss of a chance of a cure."'15 (Delay in diagnosis is the most common reason for claims in breast cancer care. $)^{16}$

- Causation. The breach of duty (negligence) must have caused the damages. The causation must have been reasonably close. If a driver drives through a stop sign, or a physician misreads a test, and someone is injured but there is no connection between the negligence and the injury, there is not tort liability.

The 4 elements of malpractice just described are raised in some way in the possible liability associated with $B R C A$ testing. We next look at the ways in which liability may arise from that testing (or lack of it). 
Underlying much of the following discussion is the "cost-benefit" consideration noted above. This concept is that the total cost (financial and health) of testing should be compared with the value of the benefits of testing, taking into account the probabilities that the testing will result in better health outcomes. BRCA testing, for example, is essentially cost-free in terms of physical risk. Its financial cost, while not trivial, is not great, and it is commonly covered by health insurance.$^{17}$ In terms of benefits, the testing has the potential for providing critical information in making treatment decisions for a meaningful percentage of patients and their families. There are many ways of analyzing the liability risks of genetic malpractice, ${ }^{7,18}$ and the following is intended to discuss some of the greatest risks related to $B R C A$ testing.

\section{Areas of liability}

The failure to recommend a test. The circumstances in which BRCA testing should be undertaken are set out by professional organizations (noted above). These recommendations are not static, however. They change from time to time. Given the potential harm caused by the failure to test in relevant circumstances, malpractice liability is certainly a possibility when the failure to recommend a test to a patient results in a cancer that might have been prevented had the genetic problem been identified in a timely manner. The circumstances in which testing should be considered continue to change, placing an obligation on clinicians to stay well informed of changing genetic understandings. Another risk is that one specialist may assume that it is the job of another specialist to order the test. Whatever the cause of the failure to test, or unnecessary delay in testing, it appears to be the primary basis for $B R C A$ liability.

The failure to properly interpret a test. Any test that is misinterpreted may lead to harm for the patient. A false negative, of course, may mean that preventive treatment that could have been undertaken will be foregone, as a "loss of a chance." On the other hand, a false positive can lead to radical, unnecessary surgery or treatment. If a misinterpretation occurred because of carelessness by the testing organization, or confusion by a practitioner, there is a likelihood of negligence. ${ }^{19}$

A different form of "misinterpretation" could be reasonable-and not negligent. Advances in scientific-medical understanding may result in the outcome of tests being reconsidered and changed. That has been the case with genetic testing and breast cancer. The availability of multiple breast cancer SNPs (single nucleotide polymorphisms), and combining this information with other risk factors for example, results in a polygenic risk score that may be at odds with the level of risk from earlier testing. ${ }^{20,21}$ This naturally leads to the question of when later, updated testing should be recommended to look for a better current interpretation. ${ }^{22,23}$

The failure to act on $B R C A$ test results. Testing is of no value, of course, if the results are not used properly. Test results or analyses that are not sent to the proper physicians, or are somehow ignored when properly directed, is a "never" event-it should never happen. It almost always would be considered negligence, and if the patient were injured, could lead to liability. Amazingly, one study found that, in genetic testing liability cases, nearly $20 \%$ of the claims arose from failure to return test results to patients. ${ }^{24}$ In addition, when a patient is found to be $B R C A$ positive, there is an obligation to discuss the options for dealing with the increased risk associated with the gene mutation(s), as well as to recommend the prudent course of action or to refer the patient to someone who will have that discussion.

Informed consent to the patient. $B R C A$ testing requires informed consent. The physical risks of the testing process are minimal, of course, but it carries a number of other emotional and family risks. The informed consent process is an invitation to an honest discussion between clinicians and patients. It should be an opportunity to discuss what the testing is, and is not, and what the test may mean for treatment. It may also be an opportunity to discuss the implications

FAST
TRACK
The several
areas of potential
liability related
to BRCA testing
include failures
to recommend,
interpret, or act
on a test; to
provide proper
informed consent;
to refer; or to
ensure that
others are
informed

FAST
TRACK

The several areas of potential liability related to BRCA testing include failures to recommend, on a test; to provide proper informed consent; to refer; or to that informed 
FAST

TRACK

Although the

opening case

was not pursued,

the time line of

events indicates

that there could

have been liability

on the part

of the

physician(s) for other members of the patient's family (noted below).

One element of informed consent is a discussion of the consequences of failure to consent, or to undertake one of the alternatives. In the case of $B R C A$ testing, this is especially important in cases in which a patient expresses a hesitancy to be tested with an "I'd rather not know philosophy." Although clinicians should not practice law, some patient concerns about discrimination may be addressed by the protection that the federal Genetic Information Nondiscrimination Act (GINA) and other laws provide (which prohibit insurance and employment discrimination based on genetic information). A good source of information about GINA and related nondiscrimination laws is provided by the National Human Genome Research Institute..$^{25}$ In addition, the National Institutes of Health has a website that may be helpful to many patients ${ }^{26}$ (and a much more complex site for health professionals). ${ }^{27}$ At the same time, courts have resisted plaintiffs/patients who have tried to use informed consent as a way of suing for failure to offer genetic testing..$^{28,29}$

The failure to refer. In some cases, a patient should be formally referred for genetics consultation. The considerations here are similar to other circumstances in modern, fast developing medical practice that require special sensitivity to those occasions in which a patient will benefit from additional expertise. It is a principle that the AMA Council on Ethical and Judicial Affairs has expressed this way: "In the absence of adequate expertise in pretest and posttest counseling, a physician should refer the patient to an appropriate specialist." ${ }^{30}$ The failure to refer, when that deviates from acceptable practice, may result in liability.

Informing others. $B R C A$ testing is an area of medicine in which results may be of great significance not only to the patient but also to the patient's family. ${ }^{31}$ Physicians should counsel patients on the importance of informing relatives about relevant results and "should make themselves available to assist patients in communicating with relatives to discuss opportunities for counseling and testing, as appropriate." ${ }^{30}$ The question may arise, however, of whether in some circumstances physicians should go a step further in ensuring relatives receive important information regarding their loved one's health. ${ }^{32}$ The law has been reluctant to impose liability to "third parties" (someone not a patient). Duties usually arise through the physicianpatient relationship. There are exceptions. Perhaps the best known has been the obligation of mental health professionals to take action to protect third parties from patients who have made believable threats against identifiable victims. ${ }^{33}$ There are indications that some courts could find, in extreme circumstances, a "duty to warn" nonpatients in some instances where it is essential to inform third parties that they should receive a specific form of genetic testing. ${ }^{34,35}$ Such a duty would, of course, have to protect the privacy rights of the patient to the maximum extent possible. A general duty of this type has not been established widely, but may be part of the future.

\section{Was there liability in our example case?}

The hypothetical case provided above suggests that there could be liability. Routine medical history by the primary care physician would have produced the fact that the patient's mother, sister, and maternal grandmother had breast cancer. That would clearly have put her in a category of those who should have received genetic testing. Yet, she was not tested until after her cancer was found. From the limited facts we have, it appears that this timeline of events would have been outside accepted practice-and negligent. The case was not pursued by the patient, however, and this may represent the current state of liability for $B R C A$ issues.

\section{The extent of liability seems to be significant}

Our discussion of liability suggests that there is significant potential for $B R C A$ testing negligence within practice, and that the damages in these cases could be substantial. Yet the predicted "tsunami" of 
malpractice lawsuits related to genetic testing has not appeared. ${ }^{36,37}$ One study of cases in the United States (through 2016) found a "slowly rising tide" of liability cases instead of a tsunami, ${ }^{24}$ as the number of claims made was low. On the other hand, the payments where damages were awarded were an order of magnitude larger than other malpractice cases-a mean of $\$ 5.3$ million and median of $\$ 2$ million. This is compared with mean values in the range of $\$ 275,000$ to $\$ 600,000$ in other areas of malpractice.

The majority of the genetic malpractice cases involve prenatal and newborn testing, and diagnosis/susceptibility/pharmacogenomic accounting for about $25 \%$ of cases. In terms of type of errors claimed, approximately $50 \%$ were diagnostic-interpretation errors, $30 \%$ failure to offer testing, nearly $20 \%$ failure to return test results to the patients, and a few remaining cases of failure to properly treat in light of genetic testing. ${ }^{24}$

Despite a few very large payments, however, the fact remains that there is a surprisingly low number of genetics malpractice cases. Gary Marchant and colleagues suggest that several reasons may account for this:

\section{References}

1. Sevilla C, Moatti JP, Reynier CJ, et al. Testing for BRCAI mutations: a cost-effective analysis. Europ J Human Genetics. 2002;10:599-606.

2. Cotton V, Kirkpatrick D. Failure to recommend genetic counseling in breast cancer: is the next wave of medical professional liability lawsuits? Contemp OB/GYN. June 1, 2017.

3. Suryavanshi M, Kumar D, Panigrahi M, et al. Detection of false positive mutations in BRCA gene by next generation sequencing. Fam Cancer. 2017;16:311-317.

4. Black L, Knoppers B, Avard D, et al. Legal liability and the uncertain nature of risk prediction: the case of breast cancer risk prediction models. Public Health Genomics. 2012;15:335-340.

5. McClintock A, Gollab A, Laya M. Breast cancer risk assessment, a step-wise approach for primary care physicians on the front lines of shared decision making. Mayo Clin Proc. 2020;95:1268-1275.

6. National Cancer Institute. The Breast Cancer Risk Assessment Tool. https://bcrisktool.cancer.gov/. Accessed February 25, 2021.

7. Neff J, Richardson G, Phelps J. Legal liabilities associated with hereditary breast and ovarian cancers. J Reprod Med. 2020;65:227-230.

8. American College of Obstetricians and Gynecologists. Practice Bulletin No 182: hereditary breast and ovarian cancer syndrome. Obstet Gynecol. 2017;130:e110-e126.

9. Sá dos Reis C, Gremion I, and Meystre NR. Study of breast implants mammography examinations for identification of suitable image quality criteria. Insights Imaging. 2020;11:3.

10. Association for Molecular Pathology v Myriad Genetics, 569 U.S. 576 (2013).
- the clinical implementation of genetic science has been slower than expected

- the lack of expertise of many physicians in genetic science

- expert witnesses have sometimes been hard to find

- the lack of understanding by plaintiffs' attorneys of genetic malpractice

- potential plaintiffs' lack of understanding of the nature of genetic testing and the harms resulting from genetic negligence..$^{17,24,37}$

\section{The tide is slowly coming in}

By all appearances, there is every reason to think that genetic malpractice will be increasing, and that the recent past of much higher damages per claim paid in the genetics area will be part of that tide. The National Human Genome Research LawSeq project has suggested a number of useful ways of dealing with the liability issues. ${ }^{18}$ In addition to the $B R C A$ issues that we have considered in this article for ObGyns, there are other critical issues of prenatal and newborn genetic testing. ${ }^{38}$ But those are topics for another day.

11. Smith SR. The Supreme Court 2012-2013: dogs, DNA, and DOMA. Register Rep. 2013;39(Fall):26-33.

12. Bal BS. An introduction to medical malpractice in the United States. Clin Orthop Relat Res. 2009;467:339-347.

13. Helling $v$ Carey, 83 Wn.2d 514, 519 P.2d 981 (1974).

14. The T.J. Hooper, 60 F.2d 737, 740 (2d Cir.1932), cert. denied 287 U.S. 662 (1932).

15. Fischer DA. Tort recovery for loss of a chance. Wake Forest $L$ Rev. 2001;36:605-655.

16. Murphy BL, Ray-Zack MD, Reddy PN, et al. Breast cancer litigation in the 21st century. Ann Surg Oncol. 2018;25:29392947.

17. Prince AE. Prevention for those who can pay: insurance reimbursement of genetic-based preventive interventions in the liminal state between health and disease. J Law Biosci. 2015;2:365-395

18. Marchant G, Barnes M, Evans JP, et al; LawSeq Liability Task Force. From genetics to genomics: facing the liability implications in clinical care. J Law Med Ethics. 2020;48:11-43.

19. Complaint, Held v Ambry Genetics Corp., No. 15-CV-8683, 2015 WL 6750024 (S.D.N.Y. Nov. 4, 2015); Order of Dismissal, Held v Ambry Genetics Corp., No. 15-CV-8683, (S.D.N.Y. Dec. 6, 2016).

20. Pederson HJ. Breast cancer risk assessment and treatment: current concepts in genetics and genomics. Contemp $O B /$ GYN. 2017; 62:A1-A4.

21. Pederson $\mathrm{HJ}$. Who needs breast cancer genetics testing? $O B G$ Manag. 2018;30:34-39.

22. Roberts JL, Foulkes A. Genetic duties. William Mary L Rev. 2020;62:143-212.

23. Thorogood A, Cook-Deegan R, Knoppers B. Public variant databases: liability? Genet Med. 2017;19:838-841.
FAST

TRACK

Although the

number of

malpractice

cases for BRCA

testing have not

reached

substantial

proportions, damages

awarded in the

existing cases

have been high

CONTINUED ON PAGE 46 
24. Marchant G, Lindor R. Genomic malpractice: an emerging tide or gentle ripple? Food Drug Law J. 2018;73:1-37.

25. National Human Genome Research Institute. Genetic discrimination. https://www.genome.gov/about-genomics /policy-issues/Genetic-Discrimination. Updated September 16, 2020. Accessed February 25, 2021.

26. National Cancer Institute. BRCA mutations: cancer risk and genetic testing. https://www.cancer.gov/about-cancer /causes-prevention/genetics/brca-fact-sheet. Reviewed November 19, 2020. Accessed February 25, 2021.

27. National Cancer Institute. Genetics of breast and gynecologic cancers (PDQ $\left.{ }^{\circ}\right)-H e a l t h$ Professional Version. https://www .cancer.gov/types/breast/hp/breast-ovarian-genetics-pdq. Updated February 12, 2021. Accessed February 25, 2021

28. Reed v Campagnolo, 630 A.2d 1145, 1152-54 (Md. 1993).

29. Munro v Regents of Univ. of Cal.,263 Cal. Rptr. 878, 885, 988 (1989).

30. AMA Council on Ethical and Judicial Affairs. AMA Code of Medical Ethics' opinions on genetic testing. Opinion 2.131. 2009;11:683-685. https://journalofethics.ama-assn .org/article/ama-code-medical-ethics-opinions-genetictesting/2009-09.

31. Gilbar R, Barnoy S. Disclosing genetic test results to the patient' relatives: how does the law influence clinical practice? J Law Technol Policy. 2019;125-168.

32. Song K. Warning third parties of genetic risks in the era of personalized medicine. U.C. Davis L Rev. 2016;49:1987-2018.

33. Tarasoff $v$ Regents of the University of California, 551 P.2d 334, 131 Cal. Rptr. 14 (Cal. 1976).

34. Safer $v$ Estate of Pack, 677 A.2d 1188 (N.J. App. 1996), cert. denied, 683 A.2d 1163 (N.J. 1996)

35. Pate v Threlkel, 661 So.2d 278 (Fla. 1995)

36. Rothstein MA. Liability issues in pharmacogenomics. Louisiana L Rev. 2005;66:117-124

37. Marchant G, Lindor R. Personalized medicine and genetic malpractice. Genet Med. 2013;15:921-922.

38. Westbrook M. Transforming the physician's standard of care in the context of whole genome sequencing technologies: finding guidance in best practice standards. Saint Louis $U J$ Health Law Policy. 2015;9:111-148. 